linkage. Until recently, for example, the cause of Young's syndrome remained obscure. Young's syndrome occurs in men with bronchiectasis and is characterised by azoospermia due to epididymal obstruction. ${ }^{16}$ No link has been found with mutations of the cystic fibrosis gene..$^{18}$ The syndrome was particularly prevalent in Britain and Australia between 1960 and $1980^{16}$ but is now rarely seen. ${ }^{17}$ In 1993 Hendry et al noted that many men with Young's syndrome had a history of Pink's disease in infancy. ${ }^{18}$ Pink's disease disappeared around 1960 with the removal of mercury from teething powders, and the disappearance of Young's syndrome some 30 years later raises the strong possibility that exposure to mercury in infancy may have caused both Pink's disease and Young's syndrome through mechanisms yet to be elucidated.

Such examples, and our growing understanding of the vulnerability of the male reproductive system to environmental factors, highlight the need for vigilance. Regulatory and research agencies need to determine the most appropriate methods of assessing the actions of agents on the reproductive system, and should undertake whatever studies are necessary to confirm or refute the emerging hypotheses. Delay may compromise the fertility of future generations.

D M de KRETSER

Director

Institute of Reproduction and Development,

Monash University,

Melbourne, Victoria 3168,

Australia
1 Irvine S, Cawood E, Richardson D, MacDonald E, Aitken J. Evidence of deteriorating semen quality in the United Kingdom: birth cohort study in $577 \mathrm{men}$ in Scotland over 11 years. BMf 1996;312:467-70.

2 Bujan L, Mansart A, Ponteonnier F, Mieusset R. Time series analysis of sperm concentration in fertile men in Toulouse, France, between 1977 and 1992. BMF 1996;312:471-2.

3 Carlsen E, Giwerman A, Keiding N, Skakkebaek NE. Evidence of decreasing quality of semen during the past 50 years. $B M 71992 ; 305: 322-7$.

4 Auger J, Kunstmann JM, Czyglik F, Jouannet P. Decline in semen quality among fertile men in Paris during the past 20 years. New Engl F Med 1995;332:281-5.

5 Sherins RJ. Are semen quality and male infertility changing? N Engl F Med 1995;332:327.

6 Bromwich P, Cohen J, Steart I, Walker A. Decline in sperm counts: an artefact of changed reference range of "normal"? $B M \Im$ 1994;309:19-22.

7 World Health Organisation Task Force on Methods for the Regulation of Male Infertility. Contraceptive efficacy of testosterone-induced azoospermia in normal men. Lancet 1990;336: 955-9.

8 Sharpe RM, Skakkebaek NE. Are oestrogens involved in falling sperm counts and disorders of the male reproductive tract? Lancet 1993;341:1392-5.

9 De Kretser DM, Kerr JB. The cytology of the testis. In: Knobil E, Neill JD, eds. Physiology and reproduction. New York: Raven Press, 1994:1177-290.

10 Orth JM, Gunsalus GM, Lamperti AA. Evidence from Sertoli cell-depleted rats indicates that spermatid numbers in adults depend on number of Sertoli cells produced during perinatal spermatid numbers in adults depend on num
development. Endocrinology 1988;122:787-94.

11 Simorangkir D, Wreford N, de Kretser DM. Increased numbers of Sertoli and germ cells in adult rat testes induced by synergistic action of transient neonatal hypothyroidism and neonatal hemicastration. $₹$ Reprod Fert 1995;104:207-13.

12 Stillman RJ. In vitro exposure to diethylstilboestrol: adverse effects on the reproductive tract and reproductive performance in male and female offspring. Am f Obstet Gynecol 1982;142:905-21.

13 Ministry of Environment and Energy, Denmark. Male reproductive health and environmental chemicals with estrogenic effects. Copenhagen: Danish Environmental Protection Agency, 1995. (Miljoprojekt No 290.)

14 Kelce WR, Stone CR, Laws SC, Gray LE, Kemppainen JA, Wilson EM. Persistent DDT metabolite $p, p^{\prime} D D E$ is a potent androgen receptor antagonist. Nature 1995;375:581-5.

15 Sharpe RM. Another DDT connection. Nature 1995;375:538-9.

16 Handelsman DJ, Conway AJ, Boylan LM, Turtle JR. Young's syndrome: obstructive azoospermia and chronic sinopulmonary infections. N Engl f Med 1994;310:3-9.

17 Friedman KJ, Teichtahl H, de Kretser DM, Temple-Smith PD, Southwick GJ, Silverman LM, et al. Screening Young syndrome patients for CFTR mutations. Am $₹$ Respir Crit Care Med et al. Screening You

18 Hendry WF, A'Hern FPA, Cole PJ. Was Young's syndrome caused by mercury exposure in childhood? BMf 1993;307:1579-82.

\title{
Flavonoids and heart disease
}

\section{Evidence of benefit still fragmentary}

A longstanding tenet of nutrition holds that people with diets rich in fruits and vegetables enjoy better health than people eating few fruits and vegetables. Consequently, research has sought the components or compounds responsible for this apparent health benefit. Much of that research currently focuses on dietary antioxidants, fuelled by our growing appreciation that damaging oxidative processes are a common biochemical link between otherwise pathophysiologically distinct diseases. ${ }^{1}$ For example, the development of early atherosclerotic lesions is now thought to be specifically promoted by low density lipoprotein particles that have been oxidatively modified, ${ }^{23}$ and oxidative damage to nucleic acids may have an important role in carcinogenesis.

Dietary antioxidants, which complement the actions of enzymatic antioxidants, are now widely recognised as including $\alpha$ tocopherol (vitamin E), ascorbic acid (vitamin C), and $\beta$ carotene (a precursor of vitamin A). Perhaps flavonoids should now be added to this list. The article by Knekt $e$ al in this issue of the $B M \mathcal{F}(\mathrm{p} 478)^{4}$ joins two other epidemiological reports $^{56}$ in suggesting a role for the flavonoids, and for quercetin in particular, in the prevention of coronary artery disease.

This Finnish study relates subjects' usual diet, as reported for the year before entry to the study, to mortality from heart disease over the subsequent 26 years. ${ }^{4}$ The findings show a modestly protective effect, after consideration of other important dietary factors such as saturated fat. (Though not commented on by the authors, flavonoids also seem to be associated with fewer deaths from diseases other than atherosclerosis.) The case for a specific cardioprotective role of quercetin comes from the data showing that apples and onions, important sources of quercetin in the Finnish diet, were the foods most strongly related to mortality risk. ${ }^{4}$ It is unfortunate that these food-specific analyses were not adjusted for total energy consumption, since an overall increase in calorific intake could easily be a marker of high physical activity or body size, both of which are themselves inversely correlated with risk of heart disease.

As intriguing as these flavonoid findings are, the epidemiological evidence is not entirely consistent. In. the atherosclerosis risk in communities study, consumption of apples was not related to thickness of the carotid artery wall (Kritchevsy, unpublished data), nor was flavonoid intake associated with heart disease in either the nurses health study or the male health professional study (Eric B Rimm, personal communication). It may be that the contribution of a particular food to cardiovascular health depends on the composition of the rest of the diet. The data of Knekt et al show a relatively low intake of vitamin $C$ in the Finnish diet, and, since quercetin may lead to sparing of vitamin C, flavonoids may be most important in populations with marginal vitamin $\mathrm{C}$ intake.

Interpretation of this information by practising clinicians (for themselves or for curious patients) is challenging. One needs to know the biochemical composition of flavonoids, their pharmacology and range of physiological effects, their potential for toxicity, and their established health benefits. Structurally, flavonoids are polyphenols of about the molecular weight of cholesterol; as such, they are small, lipid soluble compounds like $\alpha$ tocopherol and $\beta$ carotene. However, unlike these two established dietary antioxidants, flavonoids are ubiquitous in the plant kingdom and include 
many thousands of individual compounds. Particularly staggering is their list of reported actions. ${ }^{7}$ In a variety of in vitro assays flavonoids have been found to possess anti-inflammatory, antiallergic, antithrombotic, venotonic, antimicrobial, and antineoplastic activities. Some are oestrogenic, others are antithyroidal, and certain flavonoids can be mutagenic. ${ }^{8}$ On a molecular level flavonoids can modify the actions of a host of enzymes, including those involved in cell respiration and replication, drug metabolism, and immune function.

\section{Clinical relevance is unclear}

Some, though not all, of these actions of flavonoids are thought to be due to their antioxidant properties as metal chelators, free radical scavengers, and chain breaking

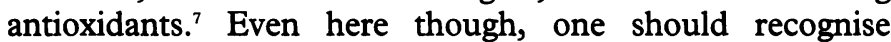
the complexity of interactions between pro-oxidants and antioxidants. A compound may act as an antioxidant in one oxidative challenge system and be neutral or even pro-oxidant in another. For example, whereas quercetin can sequester and reduce the activity of oxidant inducing metals (such as iron and copper), with an anion exchange chromatographic method for testing potential inhibitors of low density lipoprotein oxidation, quercetin was found to have pro-oxidant activity. 9

The clinical relevance of these laboratory findings is unknown. Theoretically, flavonoids may prevent coronary artery disease by inhibiting low density lipoprotein oxidation, by reducing platelet aggregation, or by reducing damage from ischaemia and reperfusion. It should also be recognised that some flavonoids have biochemical effects that could translate into toxicities in humans, particularly if taken in large doses. ${ }^{1011} \mathrm{~A}$ benefit to cardiovascular health is suggested by some epidemiological data but remains unproved in the absence of experimental studies of atherosclerosis or ran- domised clinical trials; indeed, the suspected benefits of even the classic dietary antioxidants remain to be demonstrated in clinical trials. ${ }^{12}$ The search for health promoting compounds will continue, but, given the complexities of our own biochemistry, the answers are not likely to be as simple as we would wish.

We acknowledge the advice of Dr Jukka Salonen during the preparation of this paper.

Center for Clinical Pharmacology,

University of Pittsburgh School of Medicine, Pittsburgh, PA 15260, USA

MATTHEW F MULDOON Assistant professor of medicine

STEPHEN B KRTTCHEVSKY Associate professor of preventive medicine

Division of Biostatistics and Epidemiology,

Department of Preventive Medicine,

University of Tennessee,

Memphis, TN 38163, USA

1 Ames BN, Shigenaga MK, Hagen TM. Oxidants, antioxidants, and the degenerative diseases of aging. Proc Natl Acad Sci 1993;90:7915-22.

Steinberg D, Parthasarathy S, Carew TE, Khoo JC, Witztum JL. Beyond cholesterol: modifications of low-density lipoprotein that increase its atherogenicity. N Engl F Med 1989;320:915-24.

Salonen JT, YY-Herttuala S, Yamamoto R, Butler S, Korpela H, Salonen R, et al. Autoantibody against oxidized LDL and progression of carotid atherosclerosis. Lancet 1992;339:883-7.

4 Knekt $P$, Jarvinen $R$, Reunanen A, Maatela J. Flavonoid intake and coronary mortality in Finland: a cohort study. $B M F$ 1996;312:478-81.

5 Hertog MG, Feskens EJ, Hollman PC, Katan MB, Kromhout D. Dietary antioxidant flavonoids and risk of coronary heart disease: the Zutphen elderly study. Lancet 1993;342:1007-11.

6 Hertog MG, Kromhout D, Aravanis C, Blackburn H, Buzina R, Fidanza F, et al. Flavonoid intake and long-term risk of coronary heart disease and cancer in the seven countries study. Arch Intern Med 1995;155:381-6.

7 Kandaswami C, Middleton E. Free radical scavenging and antioxidant activity of plant flavonoids. In: Armstong D, ed. Free radicals in diagnostic medicine. New York: Plenum Press, 1994.

8 Das A, Wang JH, Lien EJ. Carcinogenicity, mutagenicity and cancer preventing activities of flavonoids: a structure-system-activity relationship (SSAR) analysis. Prog Drug Res 1994;42: flavonoids:

9 Myara I, Pico I, Vedie B, Moatti N. A method to screen for the antioxidant effect of compounds on low-density lipoprotein (LDL): illustration with flavonoids. I Pharmacol Toxicol Methods

10 Jaeger A, Walti M, Neftel K. Side effects of flavonoids in medical practice. Prog Clin Biol Res 1988;280:379-94

11 Lin J, Ho Y. Flavonoid-induced acute nephropathy. Am $\mathcal{F}$ Kidney Dis 1994;23:433-40.

12 Jha $P$, Flather M, Lonn E, Farkouh M, Yusuf $S$. The antioxidant vitamins and cardiovascular disease. Ann Intern Med 1995;123:860-72.

\section{Triggering a heart attack}

\section{Compensation may be justified after physical exertion but not emotional upset}

Headlines such as "Shopkeeper dies while chasing thieves" and the ever increasing volume of letters from solicitors to cardiologists testify to the fact that the press and public are convinced that heart attacks are triggered by events. For bereaved relatives, sadness and grief may turn to loneliness and bitterness, and increasingly today to a desire to blame something or someone. The sympathetic solicitor in his office in the hospital foyer lends a willing ear and seeks expert advice. Employers and insurers also want an answer to the question of what triggers a heart attack.

The suspicion that vigorous physical effort might provoke myocardial infarction was raised some 60 years ago. ${ }^{1}$ Emotional distress has likewise been incriminated. ${ }^{2}$ More recent studies have corroborated these findings. The MILIS (Multicenter Investigation of Limitation of Infarct Size) investigators, for example, found that antecedent physical activity was present in $14 \cdot 1 \%$ of 849 cases and emotional upset in $18.4 \% .^{3}$ One American ${ }^{4}$ and one German study, ${ }^{5}$ using the novel epidemiological method known as case crossover, have suggested respectively a sixfold and twofold increase in risk of myocardial infarction in the hour after heavy physical exertion such as slow jogging, shovelling snow, swimming, pushing a lawnmower, or heavy gardening. The German study suggested further that there was an increased risk in the hours after waking or emotional upset. ${ }^{5}$ The suspicion that ventricular fibrillation and sudden cardiac death also occur more often than would be expected by chance during vigorous physical effort enjoys support from exercise testing laboratories and elsewhere. ${ }^{6}$ Only one small and rather overlooked report of 100 sudden deaths from coronary disease seems to have been undertaken in Britain, and this hinted at "acute psychological stress" as an important trigger. ${ }^{7}$ The difficulty in defining what constitutes emotional upset or acute psychological stress hardly needs emphasis; one person's stimulus is another's stress.

One event that can certainly trigger a heart attack is chest trauma. Closed chest trauma in a road traffic accident, for example, can precipitate myocardial infarction and sudden death by a variety of mechanisms. Direct myocardial contusion is usually suspected on admission from the nature of the injuries and is confirmed by electrocardiographic and cardiac enzyme changes. More often, however, cardiac damage is suspected later, when arrhythmias or heart failure are detected in an intensive care unit. Further investigation may 